\title{
Operacionalização da política de preços mínimos para os produtos da sociobiodiversidade
}

\section{Operationalization of the minimum price guarantee policy for sociobiodiversity products}

Operacionalización de la política de precios mínimos para productos de sociobiodiversidad

Emiliana Barros Cerqueira ${ }^{1}$ Jaíra Maria Alcobaça Gomes ${ }^{3}$

${ }^{1}$ Doutora em Desenvolvimento e Meio Ambiente pela Universidade Federal do Piauí (UFPI), bolsista PNPD/CAPES. E-mail: emilianacerq@gmail.com, ORCID: http://orcid.org/0000-0001-7084-3271

2 Doutora em Economia Aplicada pela Escola Superior de Agricultura "Luiz de Queiroz" (ESALQ) da Universidade de São Paulo (USP), docente do Mestrado e Doutorado em Desenvolvimento e Meio Ambiente e do Departamento de Ciências Econômicas da Universidade Federal do Piauí (UFPI). E-mail: jaira@ufpi.edu.br, ORCID: http://orcid.org/0000-0003-4664-9801 
Resumo: Objetiva-se analisar a participação econômica de dez produtos da sociobiodiversidade na economia brasileira, verificando sua espacialização no território nacional e examinando a operacionalização da Política de Preços Mínimos para a Sociobiodiversidade (PGPM-Bio). Obtiveram-se dados sobre o valor e a quantidade de produção dos dez produtos sob análise (açaí, babaçu, borracha, castanha-do-pará, carnaúba, mangaba, pequi, piaçava, pinhão, umbu) por meio do IBGE, e as informações acerca da PGPM-Bio, da CONAB. Os resultados apontaram que a extração desses recursos se sobressaiu nas Regiões Norte e Nordeste, e os principais itens, conforme o valor produzido, foram o açaí e o pó de carnaúba. Os maiores beneficiários da PGPM-Bio foram Maranhão, Bahia e Amazonas, respectivamente, com o babaçu, piaçava e borracha. Ademais, empregou-se menos da metade dos recursos destinados ao pagamento de subvenções.

Palavras-chave: políticas públicas; extrativismo; conservação ambiental.

\begin{abstract}
The objective is to analyze the economic participation of ten sociobiodiversity products in the Brazilian economy, checking their spatialization in the national territory and examining the operationalization of the Minimum Price Policy for Sociobiodiversity (PGPM-Bio). Data on the value and quantity of production of the ten products under analysis (acai, babassu, rubber, Brazil nuts, carnauba, mangaba, pequi, piassava, pine nut, umbu) were obtained from IBGE, and information about PGPM-Bio, from CONAB. The results showed that the extraction of these resources predominated in the North and Northeast Regions, and the main items, according to the value produced, were the acai and the carnauba powder. The biggest beneficiaries of PGPM-Bio were Maranhão, Bahia, and Amazonas, respectively, with babassu, piassava, and rubber. Also, less than half of the resources devoted to the payment of grants were used.
\end{abstract}

Keywords: public policies; extractivism; environmental conservation.

Resumen: El objetivo es analizar la participación económica de diez productos de la sociobiodiversidad en la economía brasileña, revisando su espacialización en el territorio nacional y examinando la operacionalización de la Política de Precio Mínimo para la Sociobiodiversidad (PGPM-Bio). Los datos sobre el valor y la cantidad de producción de los diez productos bajo análisis (açaí, babasu, caucho, nuez de Brasil, carnauba, mangaba, pequi, piasava, piñón, ombú) se obtuvieron del IBGE, y la información sobre PGPM-Bio, de CONAB. Los resultados mostraron que la extracción de estos recursos se destacó en las regiones Norte y Nordeste, y los principales rubros, según el valor producido, fueron el açaí y la carnauba en polvo. Los mayores beneficiarios de PGPM-Bio fueron Maranhão, Bahía y Amazonas, respectivamente, con babasu, piasava y caucho. Además, se utilizó menos de la mitad de los recursos dedicados al pago de subvenciones.

Palabras clave: políticas públicas; extractivismo; conservación ambiental. 


\section{INTRODUÇÃO}

Esta pesquisa tem como tema a operação da Política de Garantia de Preços Mínimos para Sociobiodiversidade (PGPM-Bio) no Brasil, entre 2009 e 2017. Ressalta-se que a Política de Garantia de Preços Mínimos (PGPM) existe desde 1943 e surgiu para apoiar a produção nacional de grãos, devendo ser acionada cada vez que o preço de mercado for inferior ao mínimo estabelecido pelo governo. A partir de 2009, a referida política passou a operar por meio de uma nova modalidade, a PGPM-Bio, amparando os produtos oriundos dos extrativos.

Justifica-se a realização deste estudo pela necessidade de serem ampliadas as discussões sobre o tema, tendo em vista, especialmente, a contemporaneidade da PGPM-Bio, sem falar do seu mérito quanto à conservação da natureza, porquanto a garantia de renda via subvenção econômica pressupõe a exploração sustentável dos recursos naturais, pois somente dessa forma é possível dar continuidade à atividade e usufruir de seus benefícios, tanto em termos de bem-estar quanto econômicos, seja pelo mercado ou pela política.

Nessa perspectiva, a problemática desta investigação alude aos produtos extrativos amparados pela PGPM-Bio, particularmente no que tange aos aspectos atinentes à sua participação econômica no produto nacional, distribuição espacial no Brasil e operacionalização por subvenções econômicas.

Como hipóteses, assume-se que a participação da sociobiodiversidade é pouco expressiva na produção nacional, dada a comercialização sob a forma de matérias-primas e o baixo valor adicionado. O extrativismo é praticado em todo o País, nomeadamente nas regiões mais pobres e menos desenvolvidas. Quanto à operacionalização, conjectura-se um cenário com excesso de crédito orçamentário - em relação ao montante de recursos demandados pelos extrativistas -, considerando que existe burocracia para acessar tal benefício e que os preços mínimos desempenham o papel de sinalizadores, estabelecendo-se abaixo dos de mercado.

Isso posto, objetiva-se analisar a participação econômica dos produtos da sociobiodiversidade apoiados pela PGPM-Bio na economia nacional brasileira, verificar a espacialização desses produtos no território nacional 
e examinar a operacionalização da política de preços mínimos para a sociobiodiversidade.

Além desta introdução, o artigo compõe-se de uma seção de: referencial teórico, que aborda a política de preços mínimos para a sociobiodiversidade, em termos conceituais, e elenca os estudos publicados sobre o tema; metodologia, que delimita a área de estudo, descrevendo os procedimentos e técnicas utilizados, a fonte das informações e a forma de análise adotada; resultados, que revelam o desdobramento dos objetivos e a discussão dos dados; e, finalizando, as conclusões.

\section{POLÍTICA DE PREÇOS MÍNIMOS PARA A SOCIOBIODIVERSIDADE}

Nesta seção, desenvolve-se o conceito de políticas públicas, delineando o surgimento da política de preços mínimos no mundo e no Brasil; os fundamentos e o papel da PGPM; as modificações ocorridas nessa política; e, por fim, citam-se os estudos sobre a PGPM-Bio.

Inicialmente, é crucial conceituar política pública. Na acepção de Souza (2006, p. 26), trata-se de um "campo do conhecimento que busca, ao mesmo tempo, 'colocar o governo em ação' e/ou analisar essa ação (variável independente) e, quando necessário, propor mudanças no rumo ou curso dessas ações (variável dependente)".

Nessa lógica, as políticas públicas são oportunas, por exemplo, quando se deseja alterar a direção de algumas atividades. No caso da produção agrícola e extrativa, como os preços sofrem oscilações decorrentes de variações climáticas, a exemplo de secas e enchentes, e do acometimento de pragas, é preciso estabelecer mecanismos capazes de minimizar essas incertezas, daí porque as políticas públicas são imprescindíveis, sobrelevando-se a PGPM.

A princípio, os preços mínimos surgiram para apoiar a produção de grãos. Em consonância com Carvalho e Silva (1993), a necessidade de instaurar políticas de preços agrícolas tornou-se vital desde a eclosão da crise de 1929, que foi responsável por evidenciar a fragilidade do setor. No entanto, seu surgimento só ocorreu em 1933, nos Estados Unidos, por meio do Agricultural Adjustment Act (Lei de Ajuste Agrícola), que se baseava em 
medidas de intervenção pública visando à redução de área de certas culturas e à garantia de preços mínimos.

No Brasil, sob influência das medidas de apoio à agricultura americana, o governo adotou duas medidas, que constituem a primeira tentativa de formalizar e institucionalizar uma política agrícola: a criação da Carteira de Crédito Agrícola e Industrial do Banco do Brasil (CREAI) - para tratar das questões de financiamento; e a criação, em 1943, da Comissão de Financiamento de Produção (CFP), vinculada ao Ministério da Fazenda, para tratar das questões de garantia de preços na comercialização, cujas decisões eram tomadas por um colegiado, e suas operações, realizadas por outros órgãos do governo, justificando a condução vacilante da PGPM. A Companhia Nacional de Abastecimento (CONAB) é o órgão responsável pelo cálculo, pela divulgação dos preços mínimos e pela operacionalização da política (COELHO, 2001).

Na teoria econômica, as políticas de preços mínimos fundamentam-se no sistema de suporte aos preços, como afirmam Pindyck e Rubinfeld (2002), sendo que seu escopo é aumentar o preço de determinado produto, de forma que os produtores dessas mercadorias possam obter uma renda mais elevada.

Apesar de sua importância, Carvalho e Silva (1993) aduzem que a PGPM foi secundária em relação à política de crédito rural, até o final da década de 1970. Contudo, diante da crise financeira do Estado, ocorreram reduções na concessão de crédito rural e a tarefa de sustentação do setor foi, então, transferida às políticas de suporte ao preço. A fim de adaptar-se a essa nova realidade, a PGPM passou por mudanças significativas: em 1979, os preços mínimos deixaram de servir como parâmetro para a determinação do crédito de custeio; em 1981, introduziu-se a indexação em seus valores; em 1988, criaram-se os preços de intervenção, com o propósito de reduzir o grau de intervenção pública nos mercados, deixando a iniciativa privada cuidar da comercialização agrícola.

Uma característica notável da PGPM, nesse período, diz respeito à vinculação dos preços mínimos à formação de estoques físicos, por meio de seus instrumentos básicos, quais sejam as Aquisições do Governo Federal (AGF) e os Empréstimos do Governo Federal (EGF). A partir da safra 1992/1996, assiste-se à sucessiva substituição, ainda que não integral, da 
formação física de estoques pelo mecanismo de garantia de preços sem formação de estoques. Criam-se, pois, novos instrumentos de intervenção: contratos de opção de venda, prêmio para escoamento do produto e valor do escoamento da produção (DELGADO; CONCEIÇÃO, 2005).

A propósito, Favro, Caldarelli e Caravieri (2014) afirmam que esses novos instrumentos intentavam, sobretudo, a diminuição da intervenção governamental, comprovada a partir de 2010, com o decrescimento de gastos públicos destinados a essa política.

Na safra 2008/2009, a PGPM passou a operar, também, em outra modalidade, a PGPM-Bio, englobando, preliminarmente, sete produtos da sociobiodiversidade, a saber: açaí, babaçu, borracha, castanha-do-pará, carnaúba, pequi e piaçava. Com isso, beneficiou Povos e Comunidades Tradicionais e Agricultores Familiares (PCTAFs), com o desígnio de aumentar a capacidade produtiva e de autossustentação desses povos (BRASIL, 2009).

A inclusão desses produtos na PGPM foi condicionada pela Política Nacional da Biodiversidade (PNB) - Decreto n. 4.399, de 22 de agosto de 2002 -, resultante de acordos que o Brasil assinou durante a Conferência das Nações Unidas sobre Meio Ambiente e Desenvolvimento (CNUMAD) - Convenção sobre Diversidade Biológica (CDB), Política Nacional do Meio Ambiente, Declaração do Rio, Agenda 21-, bem como demais normas sobre biodiversidade, mediante os quais se comprometeu a assegurar a preservação de sua rica diversidade biológica, composta por produtos com pouca visibilidade na economia formal, dada a percepção de que este mercado representa grandes possibilidades para o desenvolvimento sustentável, ao demonstrar a viabilidade de unir o uso e a conservação da biodiversidade com atividades de geração de renda (BRASIL, 2009).

A PNB tem como intuito promover, de forma unificada, a conservação da biodiversidade e a utilização sustentável de seus componentes, além de repartir, justa e equitativamente, os benefícios derivados da utilização de recursos genéticos, de componentes do patrimônio genético e dos conhecimentos tradicionais associados a esses recursos (BRASIL, 2002).

A biodiversidade do País exigiu a adoção de políticas complementares à política nacional referenciada, de modo que focalize a definição de desenvolvimento territorial e ampare os Povos e as Comunidades Tradicionais, 
classificados, em conformidade com Decreto 6.040, de 7 de fevereiro de 2007, como

[...] grupos culturalmente diferenciados e que se reconhecem como tais, que possuem formas próprias de organização social, que ocupam e usam territórios e recursos naturais como condição para sua reprodução cultural, social, religiosa, ancestral e econômica, utilizando conhecimentos, inovações e práticas gerados e transmitidos pela tradição (BRASIL, 2007, p. 316).

A Política Nacional de Desenvolvimento Sustentável dos Povos e Comunidades Tradicionais (PNPCT), instituída pelo Decreto n. 6.040, de 7 de fevereiro de 2007, tem como principal finalidade promover o desenvolvimento sustentável dos povos e das comunidades tradicionais, com ênfase no reconhecimento, no fortalecimento e na garantia de seus direitos territoriais, sociais, ambientais, econômicos e culturais, com respeito e valorização à sua identidade, suas formas de organização e suas instituições.

Com efeito, a adoção de políticas que visam ao apoio à comercialização de produtos da sociobiodiversidade entrelaça-se a dois objetivos que, juntos, representam uma possibilidade para o alcance do desenvolvimento sustentável: a comercialização de produtos ambientais, com valor social e econômico; salvaguardar áreas extrativas, consideradas de baixo valor por outras ocupações, no tocante à substituição, ao garantir renda mínima ao trabalhador.

Dessa forma, apreende-se que a PGPM-Bio ampliou a abrangência da PGPM convencional, ao incluir os produtos extrativos, repercutindo na valorização os PCTAFs, e do meio ambiente, além da criação de um novo instrumento de operação - as subvenções econômicas, que se alicerçam no pagamento da diferença entre os preços de mercado e mínimo, diminuindo, por conseguinte, o ônus governamental.

Na direção de enaltecer os recursos naturais, Lima, Cardoso Jr. e Lunas (2017) vislumbram a PGPM-Bio como instrumento de intervenção estatal para a conservação do meio ambiente, posto que, ao tencionar a manutenção da cultura, são realizados reflorestamentos, áreas degradadas são recuperadas e boas práticas de manejo são propagadas.

Sem embargo, sublinha-se que, apesar de a PGPM-Bio ser teoricamente bem-intencionada, estudos empíricos assinalam limitações à sua 
operacionalização, sendo a principal delas apontada por Cerqueira e Gomes (2015), que, ao estudarem o mercado do pó e da cera de carnaúba, constataram que os preços mínimos se situam abaixo dos de mercado, na maioria dos anos. Outrossim, revelam que há falta de informação dos extrativistas sobre essa política, dificultando o acesso a ela.

Corroborando essa ideia, Lima, Cardoso e Lunas (2017) ratificam que o êxito da política depende de sua larga disseminação entre os produtores, e acrescentam outros motivos, como a falta de mercados formais, que leva esses produtos a serem comercializados sem a emissão de nota fiscal - documento necessário para a comprovação de que a venda foi realizada por preço inferior ao mínimo -, além do preço pouco atraente pago pelo governo - a título de subvenção -, em face do processo burocrático envolvido no acesso à PGPM.

Todavia, existem outros entraves. No entendimento de Viana (2015), por exemplo, há a necessidade de ampliar o acesso dos extrativistas à documentação básica para ter acesso ao benefício concedido pela PGPM-Bio, sobretudo à Declaração de Aptidão ao Programa Nacional de Fortalecimento da Agricultura Familiar (DAP).

Destarte, a PGPM-Bio reúne aspectos econômico, social e ambiental favoráveis ao extrativismo, assumindo, inclusive, proeminência para a integração ecológica com o desenvolvimento econômico. Aliás, incorpora a conservação nas decisões políticas, embora as dificuldades relacionadas à sua operacionalização possam torná-la inócua. Tendo isso em vista, concebe-se a inescusabilidade de perscrutar a PGPM-Bio, mormente quanto às suas operações.

A seção a seguir delineia os procedimentos metodológicos utilizadas nesta pesquisa.

\section{METODOLOGIA}

A área de estudo abrange todo o território brasileiro e engloba o período de 2009 a 2017. Os produtos analisados foram escolhidos a partir de dois critérios: ser beneficiado pela PGPM-Bio; e constar na base de dados do Sistema IBGE de Recuperação Automática (SIDRA). Desse modo, optou-se pelos dez produtos elencados no quadro 1. 
Quadro 1 - Lista dos produtos da sociobiodiversidade estudados

\begin{tabular}{|l|l|}
\hline DENOMINAÇÃO POPULAR & NOME CIENTíFICO \\
\hline Açaí & Euterpe oleracea Mart. \\
\hline Babaçu & Orbignya phalerata Mart. \\
\hline Borracha & Hevea brasiliensis (Willd. ex Juss.) Mull. Arg. \\
\hline Castanha-do-pará & Bertholletia excelsa Bonpl. \\
\hline Carnaúba & Copernicia prunifera (Mill.) H. E. Moore \\
\hline Mangaba & Hancornia speciosa Gomes \\
\hline Pequi & Caryocar coriaceum Wittm. \\
\hline Piaçava & Attalea funifera Mart. \\
\hline Pinhão & Araucaria angustifolia, (Bert) O Ktze \\
\hline Umbu & Spondias tuberosa Arruda \\
\hline
\end{tabular}

Fonte: elaborado pelas autoras.

Visando à análise da participação econômica dos produtos da sociobiodiversidade na economia nacional brasileira, inicialmente, busca-se compreender a distribuição do Produto Interno Bruto (PIB) entre as regiões e os estados brasileiros, em conformidade com o setor produtivo, detalhando o valor adicionado bruto dos serviços, da indústria, da agropecuária e da administração, defesa, educação e saúde públicas e seguridade social, com a finalidade de identificar as concentrações, em termos de localização e atividade, ou seja, apontar as regiões com o maior PIB e o setor de atividade predominante.

Nesse ensejo, utilizaram-se as informações disponíveis no site do IBGE/ SIDRA/PIB dos municípios, referentes ao ano de 2015. De posse desses elementos, traça-se a evolução do valor adicionado bruto do PIB nacional, de acordo com setor produtivo, no período compreendido entre 2002 e 2015, com o intuito de observar em qual deles ocorre mais oscilação. Os dados foram igualmente obtidos no site do IBGE, cujos valores foram deflacionados, por meio do deflator implícito anual do IBGE, referência 2010, tendo como base o ano de 2002 - no cálculo, utilizaram-se taxas acumuladas.

Por fim, delimita-se a participação do extrativismo no PIB do País, exibindo o percentual dessa atividade nas cinco regiões brasileiras, bem como dos dez produtos investigados, com vistas a designar aqueles que 
apresentaram os maiores valores produzidos. Para tal, lança-se mão de informações disponibilizadas no site do IBGE/SIDRA/Produção da Extração Vegetal e da Silvicultura (PEVS), relativas ao valor e à quantidade produzidos pelos dez produtos no ano de 2016.

Para alcançar o segundo objetivo, qual seja verificar a espacialização desses produtos no território nacional, empregaram-se os dados da PEVS para identificar as localidades que os exploram. Com isso, foi possível construir uma tabela de atributos no ArcGIS 10.0, contendo a distribuição geográfica dos produtos extrativos em uma base cartográfica.

A fim de examinar a operacionalização da PGPM-Bio, adotaram-se dados acerca do valor orçado e operacionalizado pela política, destacando-se o valor das subvenções pagas por estado e por produto. Para mais, verificaram-se os preços de mercado e mínimo. Tais variáveis foram repassadas por e-mail pelo analista de operações do Setor de Apoio à Logística e Gestão da Oferta da CONAB, PI, e englobam o período de 2009 a 2017.

A princípio, compara-se o crédito orçamentário destinado à PGPM-Bio com o recurso efetivamente operacionalizado; em seguida, apresenta-se a operacionalização por estado, conforme o valor utilizado, destacando-se os produtos beneficiados via subvenções. Isso contribui para evidenciar as cadeias mais fragilizadas e as que se beneficiam com a política. A título de informação, o cálculo do valor de subvenção é realizado pela fórmula a seguir:

VSP $=$ QP $\times(P M-P V)$, limitado a o LSPA

Em que:

VSP = Valor da subvenção a ser pago;

$\mathrm{QP}=$ Quantidade do produto (constante da nota fiscal de venda ou de entrada);

$\mathrm{PM}=$ Preço mínimo;

$\mathrm{PV}=$ Preço de venda constante da nota fiscal de venda ou de entrada; LSPA = Limite de subvenção por produto/ano.

Dando seguimento, mostra-se a evolução dos preços de mercado - que equivale ao preço médio mensal - e mínimo dos dez itens, descrevendo-os estatisticamente. Nomeadamente, especificam-se o número de 
observações, mínimo, máximo, média, desvio-padrão e variância. Esses preços foram deflacionados pelo Índice Geral de Preços - Disponibilidade Interna (IGP-DI), tendo como base o mês de dezembro de 2017.

As análises dos resultados basearam-se em elementos gráficos, cartográficos e tabulares. A seção seguinte expõe os desdobramentos dos objetivos deste estudo.

\section{PARTICIPAÇÃO DA SOCIOBIODIVERSIDADE NA ECONOMIA NACIONAL E A OPERAÇÃO DA PGPM-BIO}

A partir das etapas metodológicas descritas na seção anterior, adquire-se como resultado que o percentual do valor adicionado bruto por setores produtivos distribui-se entre as regiões e os estados brasileiros de modo desigual, como se visualiza no gráfico 1.

Gráfico 1 - Participação percentual no valor adicionado bruto por atividade econômica

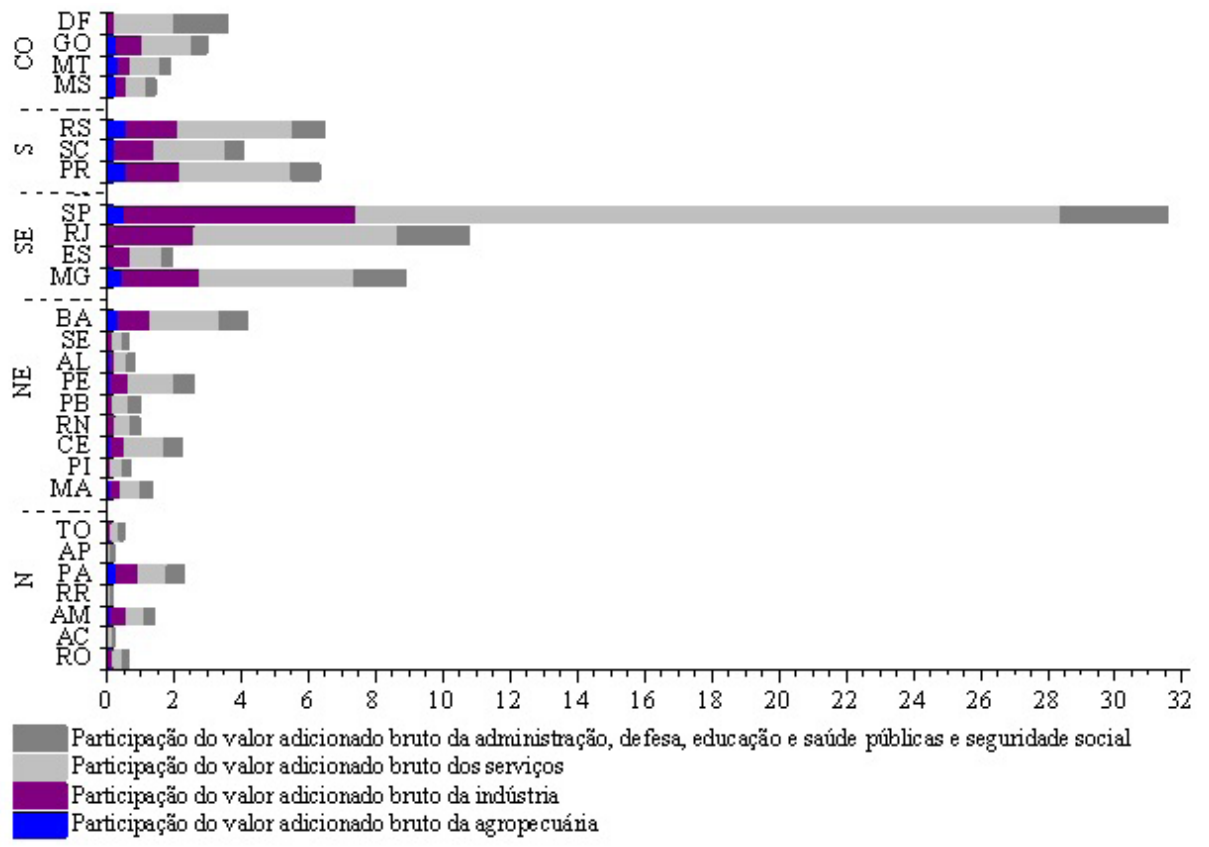

Fonte: Elaborado pelas autoras, a partir de dados básicos relativos ao PIB dos municípios (IBGE, 2015). 
De acordo com o gráfico 1, a Região Sudeste destaca-se, participando com 53,1\% do valor adicionado bruto nacional - particularmente São Paulo (31,5\%), com predominância das atividades ligadas aos setores de serviço e industrial. Até mesmo a agropecuária apresenta percentuais maiores no Sul $(1,4 \%)$ e Sudeste (1,1\%), enquanto o Centro-Oeste e o Nordeste tiveram $0,9 \%$ cada um e o Norte, 0,6\%. A Região Norte foi a que alcançou menor participação em todos os setores. O ramo de serviços sobressai-se em todos os estados, exceto em Roraima.

Arbache (2015) elenca alguns fatores que justificam a predominância do setor de serviços na economia brasileira. São eles: elevada heterogeneidade dos segmentos de serviços, abrangendo atividades com os mais variados graus de dinamismo; perda de força dos demais setores; crescimento da população urbana e a consequente transformação demográfica; e os relativamente baixos custos de entrada.

Dados do IBGE (2015) dão conta de que, em 2015, o valor adicionado bruto a preços correntes total (em mil reais) foi de $\mathrm{R} \$ 5.155 .600 .999,00$, dos quais $55,3 \%$ são provenientes dos serviços, $22,5 \%$ da indústria, $17,2 \%$ da administração, defesa, educação e saúde públicas e seguridade social, e 5,0\% da agropecuária. ${ }^{3}$

Ratifica-se, portanto, que, apesar de ter importância absoluta, tendo em vista que fornece matéria-prima para os demais setores, a atividade primária representa uma pequena parcela do valor adicionado bruto nacional, em termos relativos.

Coadunando Vieira (1998), o setor primário da economia brasileira baseia-se, predominantemente, na comercialização de commodities, que se caracterizam pelo uso pouco intensivo de tecnologia, baixo valor agregado, muitos produtores, sendo que os produtos ofertados apresentam atributos semelhantes e os produtores individuais não têm poder para interferir na formação de preços. Isso explicaria sua pequena participação relativa no PIB.

${ }^{3}$ O IBGE (2016) considera como segmentos da agropecuária: a agricultura - Produção Agrícola Municipal (PAM); a pecuária - Pesquisa da Pecuária Municipal (PPM); a produção florestal - PEVS; a pesca - Censo Demográfico, pessoal ocupado na atividade; e a aquicultura (PPM). 
Ilustra-se a evolução do valor adicionado bruto da economia brasileira, por setor produtivo, de 2002 a 2015, no gráfico 2. Perquirindo-se a evolução dos setores da economia, de acordo com o valor adicionado bruto a preços constantes, nota-se que o agropecuário demonstra a maior oscilação, entre 2002 e 2015, sendo, portanto, o mais instável.

Explica-se tal fato pela própria configuração da atividade, que está sujeita a modificações climáticas, resultando em maior variabilidade na quantidade e no preço desses produtos.

Gráfico 2 - Evolução do valor adicionado bruto nacional por setor produtivo, em mil reais

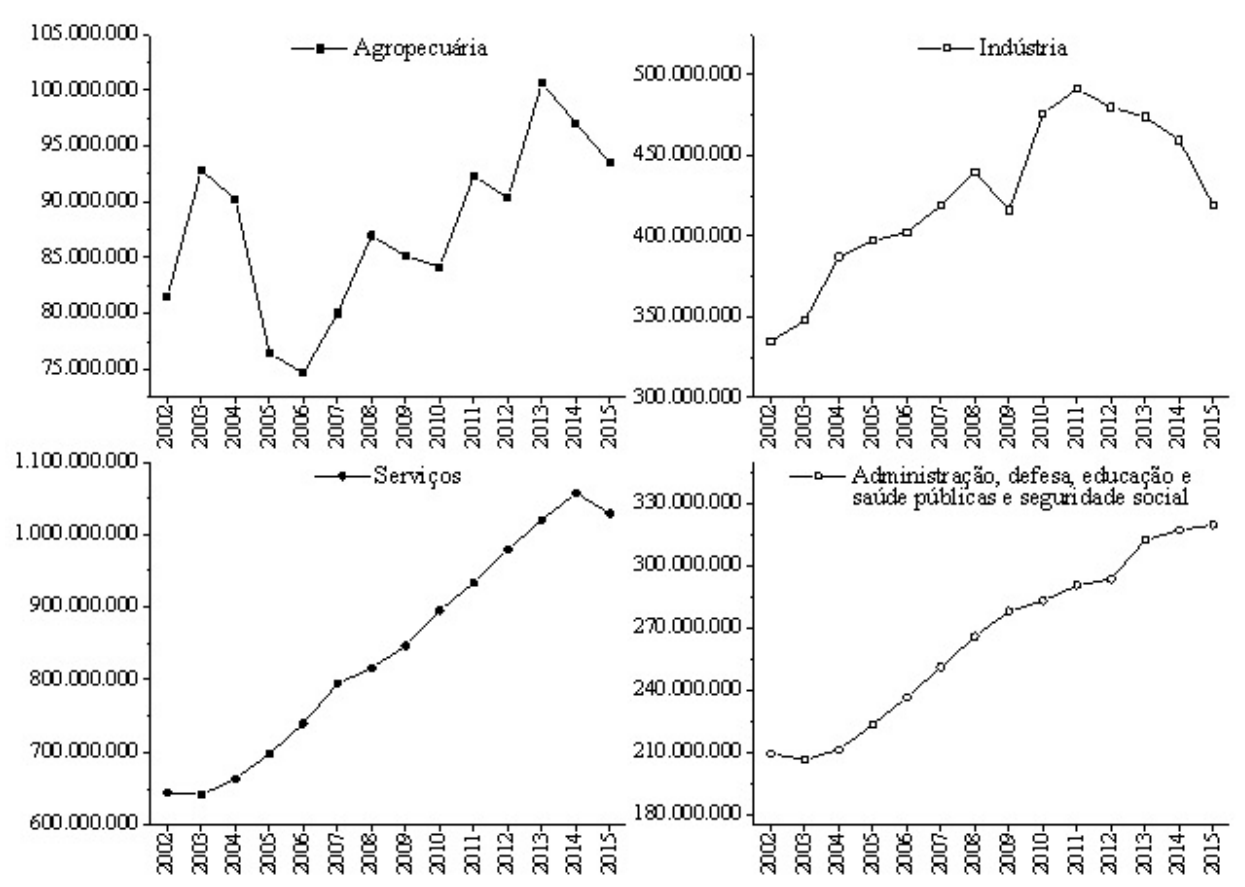

Fonte: elaborado pelas autoras, a partir de dados básicos relativos ao PIB dos municípios (IBGE, 2015).

O extrativismo vegetal é uma das atividades que compõem a agropecuária. Dados do IBGE (2015) indicam que o valor da produção na extração vegetal ( $R \$ 4.719 .115,00$, em mil reais) foi equivalente a $1,8 \%$ do valor 
adicionado bruto da agropecuária. Em 2016, o valor da produção extrativa foi de $R \$ 4.426 .293,00$, em mil reais. Logo, concebe-se a redução no valor produzido entre esses dois anos. Desse total, os dez produtos ora analisados abrangem um percentual de 24,6\% (R\$1.090.445,00, em mil reais), e sua distribuição, conforme as regiões da Federação, desvela-se no gráfico 3.

Gráfico 3 - Participação relativa das regiões brasileiras no valor de produção dos dez produtos analisados

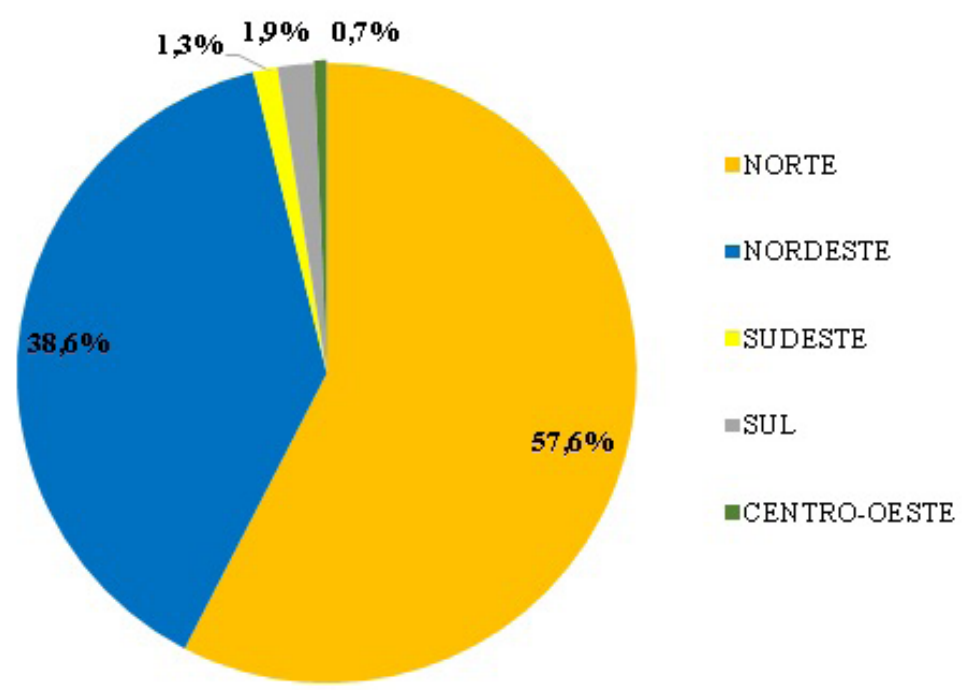

Fonte: Elaborado pelas autoras, a partir de dados básicos do IBGE - PEVS (2016).

Os dez produtos examinados neste estudo encontram maior expressividade no Norte e Nordeste brasileiro, consoante ao valor produzido em 2016. As duas regiões englobam, juntas, 96,2\% do total, aprovando o fato de que elas são as menos industrializadas e urbanizadas. Entre esses produtos, os de maior relevância são o açaí (47,2\%), no Norte, e o pó de carnaúba $(17,2 \%)$, no Nordeste.

Nos estudos de Nogueira, Santana e Garcia (2013) sobre a dinâmica do mercado de açaí, entre 1994 e 2009, os autores averiguaram que o fruto apresentou uma demanda crescente, tanto nacional quanto internacional, pressionando os preços para cima, uma vez que essa mostrou-se $26,7 \%$ 
maior que a oferta. Os pesquisadores atribuíram esse cenário às novas configurações de consumo, decorrentes dos benefícios associados ao uso desse produto, enquanto bem funcional e energético.

Por sua vez, o pó cerífero de carnaúba constitui matéria-prima para a produção de cera que, conforme dados do AliceWeb (2018), é um dos itens mais relevantes da pauta de exportação de seus principais produtores, o Piauí e o Ceará. O gráfico 4 ilustra a parcela de cada produto no valor e na quantidade produzidos nesse mesmo ano.

Gráfico 4 - Participação (\%) dos dez produtos da sociobiodiversidade: quantidade (a) e o valor produzido (b)

(a)

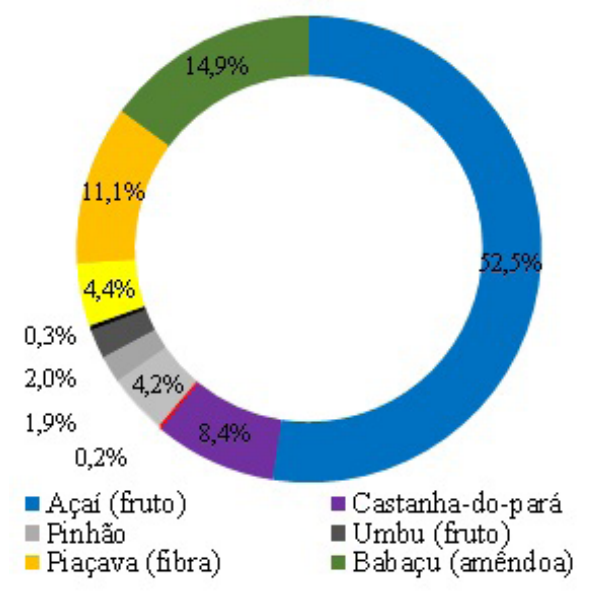

(b)

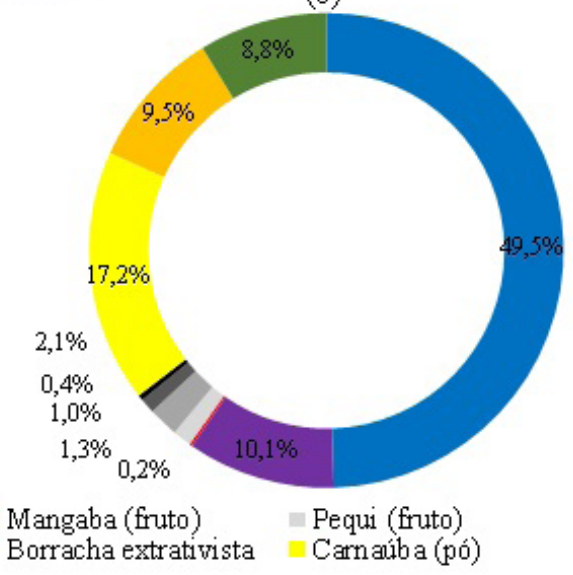

Fonte: Elaborado pelas autoras, a partir de dados básicos do IBGE - PEVS (2016).

Observa-se, desse modo, que, entre os dez produtos da sociobiodiversidade, avultam-se cinco: fruto de açaí, pó de carnaúba, castanha-do-pará, fibra de piaçava e amêndoa de babaçu. O fruto de açaí é o principal deles, tanto sob a ótica do valor quanto de quantidade. Já o pó de carnaúba, em termos relativos, tem significativa fração do valor total $(17,2 \%)$, apesar da pouca representatividade na quantidade produzida (4,4\%).

O mapa 1 mostra a disposição geográfica desses produtos no território nacional. 
Mapa 1 - Distribuição geográfica dos dez produtos da sociobiodiversidade, no Brasil, em 2016

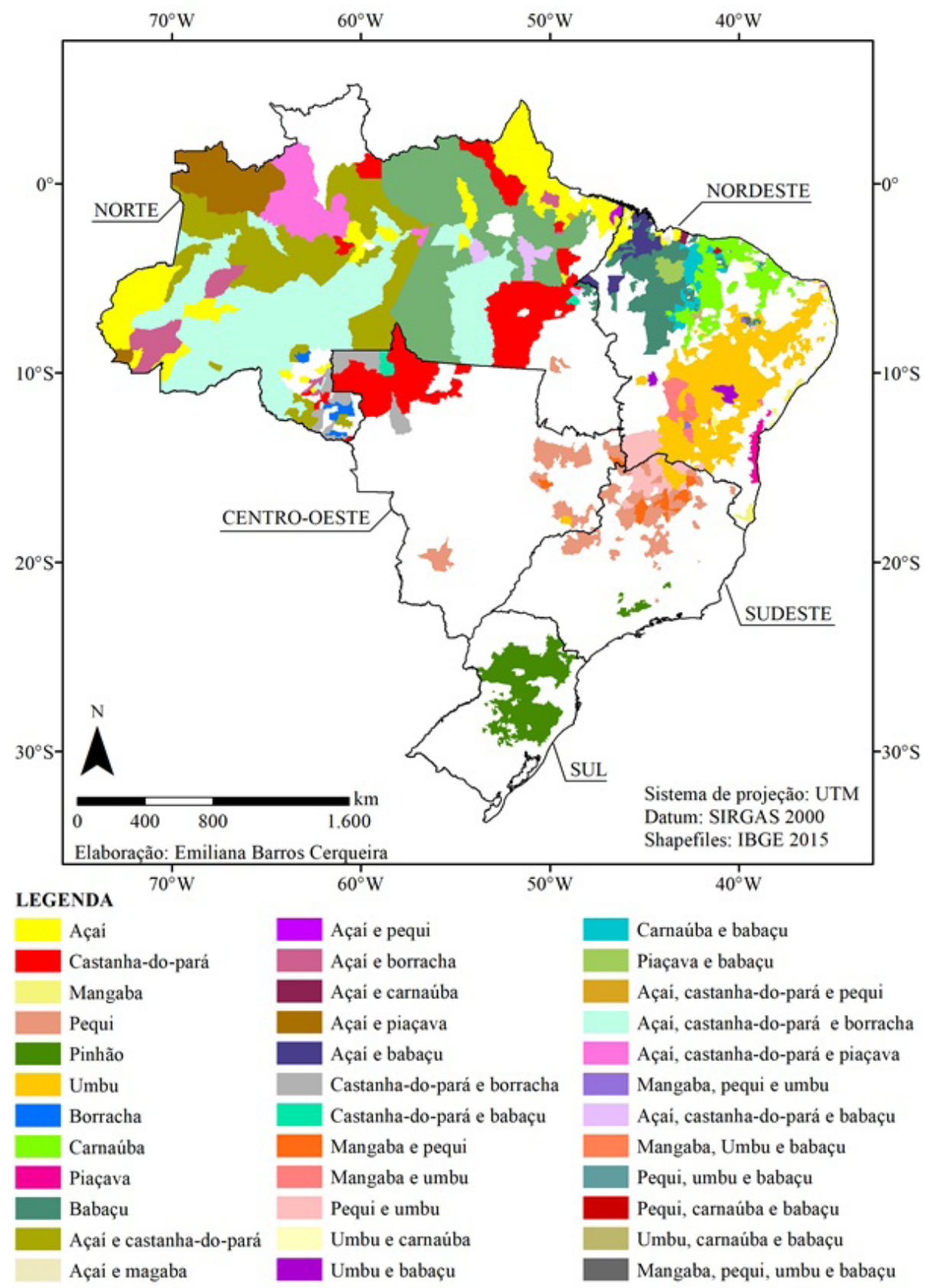

Fonte: elaborado pelas autoras, a partir de dados básicos do IBGE - PEVS (2016). 
No mapa 1, nota-se que a Região Norte concentra as produções de açaí (cerca de 95,3\% do total nacional), castanha-do-pará (94,6\%) e borracha (98,7\%), além de pequi, piaçava e babaçu. No Nordeste, predominam as extrações do pó de carnaúba (100\% do valor total da extração do país), babaçu (99,6\%), mangaba $(91,3 \%)$ e umbu (87,5\%), mas também há exploração do açaí, pequi e piaçava. Nas demais regiões, sobressai-se o extrativismo do pinhão (Sul e Sudeste) e do pequi (Sudeste e Centro-Oeste). É oportuno frisar que a espacialização geográfica reflete a riqueza biológica, as condições e a diversidade dos ecossistemas brasileiros, tendo em vista que as espécies em questão são nativas.

Como relatado, essas espécies recebem o apoio do governo, por meio da PGPM-Bio, que vislumbra um bônus ao produtor extrativista que vender seu produto por um preço inferior ao estabelecido pela política. Para tanto, a PGPM-Bio utiliza o instrumento de subvenção econômica.

A tabela 1 exibe o volume de recursos destinado às operações da PGPM-Bio e o valor total de subvenções pagas por ano.

Tabela 1 - Recursos destinados à PGPM-Bio e valor de subvenções pagas, em mil reais

\begin{tabular}{c|c|c|c}
\hline ANO & VALOR DESTINADO R\$ & VALOR OPERACIONALIZADO R\$ & $\boldsymbol{\%}$ \\
\hline 2009 & $10.000,00$ & $1.031,99$ & 10,32 \\
2010 & $25.000,00$ & $3.026,16$ & 12,10 \\
2011 & $5.000,00$ & $1.965,03$ & 39,30 \\
2012 & $15.000,00$ & $5.236,85$ & 34,91 \\
2013 & $20.000,00$ & $7.303,61$ & 36,52 \\
2014 & $30.000,00$ & $5.062,82$ & 16,88 \\
2015 & $40.000,00$ & $5.047,78$ & 12,62 \\
2016 & $50.000,00$ & $5.527,07$ & 11,05 \\
2017 & $8.000,00$ & $6.756,08$ & 84,45 \\
\hline
\end{tabular}

Fonte: Elaboração própria. Dados básicos: CONAB (2018).

A análise da tabela 1 permite constatar que a porcentagem de recursos usados, em relação ao total disponibilizado, não chega a 40\%, exceto em 2017, quando registrou uma taxa de $84,45 \%$. Sobre isso, Viana (2015), 
ao analisar a operacionalização da PGPM-Bio de 2009 a 2013, observou que havia espaço para ampliar a atuação política, uma vez que, do valor alocado para o pagamento de subvenções, apenas $25 \%$ havia sido utilizado. Entretanto, ao comparar os dois últimos anos apresentados na tabela 1, o que se observou foi uma expressiva redução no valor orçado - cerca de 84\% -, passando de cinquenta milhões de reais, em 2016, para oito milhões de reais, em 2017, apesar de o valor pago ter sido superior.

Corrobora-se, então, o apontamento de Cerqueira e Gomes (2015), para quem a política de preços mínimos exerce um papel de sinalizador ao mercado, informando o preço de venda que cobrirá os custos de produção.

Quanto à operacionalização da política de preços mínimos para a sociobiodiversidade, por unidade da Federação, o gráfico 5 revela o volume de recursos gastos com o pagamento de subvenções econômicas entre 2009 e 2017.

Gráfico 5 - Operacionalização da PGPM-Bio, segundo o percentual do valor de subvenções econômicas pagas

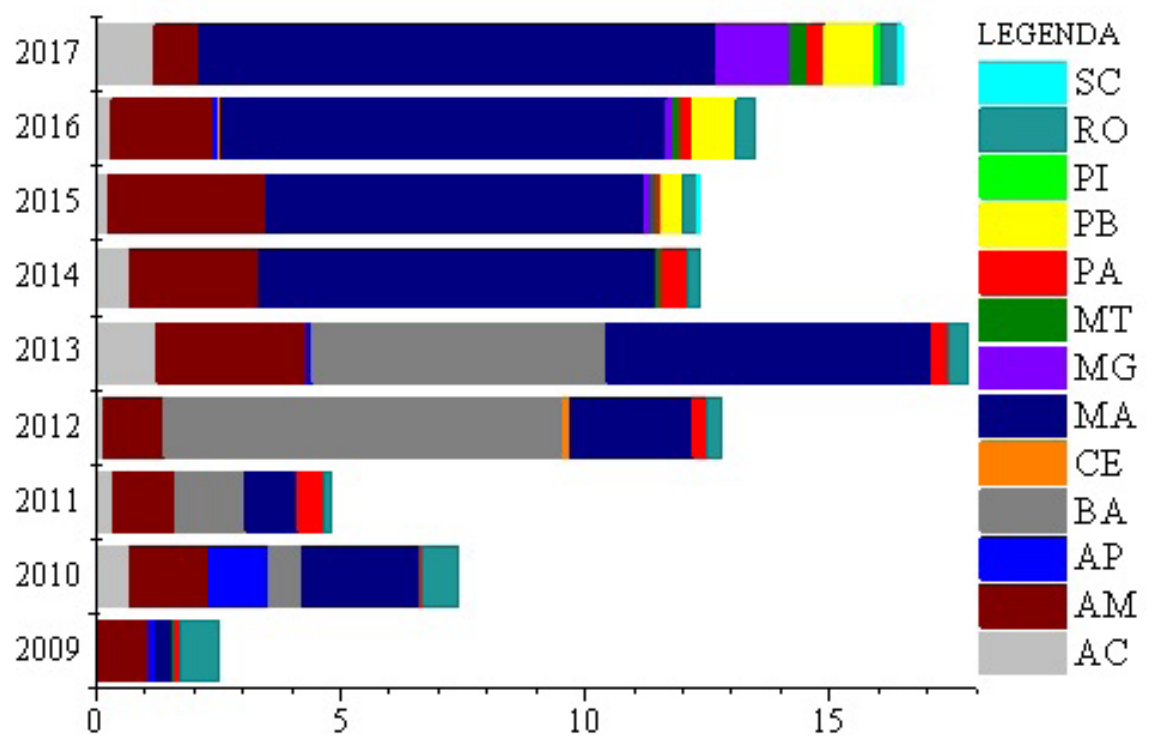

Fonte: elaborado pelas autoras, a partir de dados básicos da CONAB (2018). 
O volume de recursos despendido pelo governo com a PGPM-Bio, de 2009 a 2017, totalizou um montante de R\$ 40.957.391,33 (quarenta milhões, novecentos e cinquenta e sete mil, trezentos e noventa e um reais e trinta e três centavos). Do exposto no gráfico 5, depreende-se que apenas treze estados beneficiaram extrativistas por meio dessa política. Aqueles que concretizaram o maior número de operações, no período investigado, foram Maranhão (48,58\%), Amazonas (17,16\%) e Bahia (16,28\%). Em 2009, assistiu-se ao menor número de execuções da PGPM-Bio, e em 2013, ao maior.

No Acre, as subvenções pagas destinaram-se aos extrativistas de borracha e castanha-do-pará. No Amazonas, de açaí, borracha, castanha-do-pará e piaçava. Em alguns estados, apenas um produto foi subvencionado, como é o caso da castanha-do-pará, no Amapá; da piaçava, na Bahia; da borracha, em Mato Grosso; da mangaba, na Paraíba; do pinhão, em Santa Catarina; e do babaçu, no Ceará, no Maranhão e no Piauí (CONAB, 2018).

É meritório resgatar que a operacionalização da PGPM-Bio tem alguns entraves, como indicaram Cerqueira e Gomes (2015), Viana (2015) e Lima, Cardoso e Lunas (2017): preços de mercado superiores aos mínimos; desconhecimento da política ou das formas de acessá-la, por parte dos extrativistas; falta de mercados formais, dificultando a emissão de nota fiscal; os extrativistas não possuem DAP - documento necessário para usufruir do benefício, mas que envolve um processo burocrático.

Quanto aos preços mínimos e de mercado do babaçu, borracha, mangaba, pequi, umbu, açaí, piaçava, castanha-do-pará, pinhão, pó e cera de carnaúba, de 2009 a 2017, apresenta-se na tabela 2 uma descrição estatística desses dados, detalhando o número de observações; o valor máximo e mínimo; a média; o desvio-padrão. Ademais, a variância de cada um e a evolução deles ao longo desse período dispõem-se no gráfico 6. 
Tabela 2 - Estatística descritiva dos preços mínimos (Min) e de mercado (Merc)

\begin{tabular}{|c|c|c|c|c|c|c|c|c|c|c|c|c|}
\hline \multirow[t]{2}{*}{ Produto } & \multicolumn{2}{|c|}{$\begin{array}{c}\text { N. de } \\
\text { observações }\end{array}$} & \multicolumn{2}{|c|}{ Mínimo } & \multicolumn{2}{|c|}{ Máximo } & \multicolumn{2}{|c|}{ Média } & \multicolumn{2}{|c|}{ Desvio-padrão } & \multicolumn{2}{|c|}{ Variância } \\
\hline & Merc & Min & Merc & Min & Merc & Min & Merc & Min & Merc & Min & Merc & Min \\
\hline Açaí & 108 & 108 & 1,19 & 0,95 & 3,05 & 1,36 & 2,08 & 1,18 & 0,38 & 0,13 & 0,14 & 0,02 \\
\hline Babaçu & 108 & 108 & 1,32 & 1,97 & 2,55 & 3,16 & 1,58 & 2,56 & 0,20 & 0,37 & 0,04 & 0,14 \\
\hline Borracha & 108 & 108 & 1,88 & 4,73 & 4,57 & 6,22 & 2,79 & 5,41 & 0,79 & 0,37 & 0,62 & 0,13 \\
\hline Castanha & 108 & 108 & 1,05 & 1,19 & 7,92 & 1,70 & 2,90 & 1,45 & 1,47 & 0,14 & 2,16 & 0,02 \\
\hline Cera & 108 & 108 & 9,71 & 6,44 & 21,93 & 14,00 & 13,98 & 10,50 & 3,52 & 2,09 & 12,41 & 4,37 \\
\hline Mangaba* & 84 & 84 & 0,65 & 1,21 & 3,78 & 1,67 & 2,52 & 1,45 & 0,65 & 0,14 & 0,42 & 0,02 \\
\hline Pequi & 108 & 108 & 0,49 & 0,40 & 23,46 & 0,58 & 1,90 & 0,49 & 3,64 & 0,07 & 13,25 & 0,00 \\
\hline Piaçava & 108 & 108 & 2,11 & 1,71 & 2,91 & 2,74 & 2,45 & 2,19 & 0,16 & 0,30 & 0,02 & 0,09 \\
\hline Pinhão** & 18 & 18 & 2,82 & 2,28 & 8,10 & 2,73 & 4,70 & 2,60 & 1,66 & 0,15 & 2,77 & 0,02 \\
\hline Pó tipo B & 108 & 108 & 5,69 & 3,74 & 13,05 & 8,51 & 7,95 & 6,32 & 2,11 & 1,30 & 4,45 & 1,69 \\
\hline Umbu*** & 89 & 89 & 0,27 & 0,51 & 2,72 & 0,66 & 1,09 & 0,59 & 0,52 & 0,05 & 0,27 & 0,00 \\
\hline
\end{tabular}

Legenda: Sinal convencional utilizado:

0,00 Dado numérico igual a zero resultante de arredondamento.

* Dados disponíveis a partir de jan./2011.

** Dados disponíveis de maio/2014 - set./2014; abr./2015 - jul./2015; abr./2016 ago./2016; e abr./2017 - jul./2017.

*** Dados disponíveis a partir de ago./2010.

Fonte: elaborado pelas autoras, a partir de dados básicos da CONAB (2018).

Sobre os preços de mercado, pelos dados da tabela 2, assimila-se que o pequi, a cera e o pó de carnaúba foram os que se afiguraram com as maiores dispersões em torno da média, exprimindo variâncias de, respectivamente, 13,25, 12,41 e 4,45. Por outro lado, a piaçava e o babaçu refletiram as menores. Os preços mínimos da cera e do pó de carnaúba também se distinguem por exibirem as maiores distâncias em relação aos valores centrais.

Como se vê no gráfico 6, o babaçu e a borracha expressaram o preço mínimo superior ao de mercado durante todo o período analisado, o que justifica a quantidade de operações realizadas em relação a esses produtos. Entre 2009 e 2011, a piaçava teve comportamento análogo, porém o preço de mercado superou o mínimo após esse período. 
Gráfico 6 - Evolução real dos preços de mercado e mínimo dos produtos da sociobiodiversidade analisados
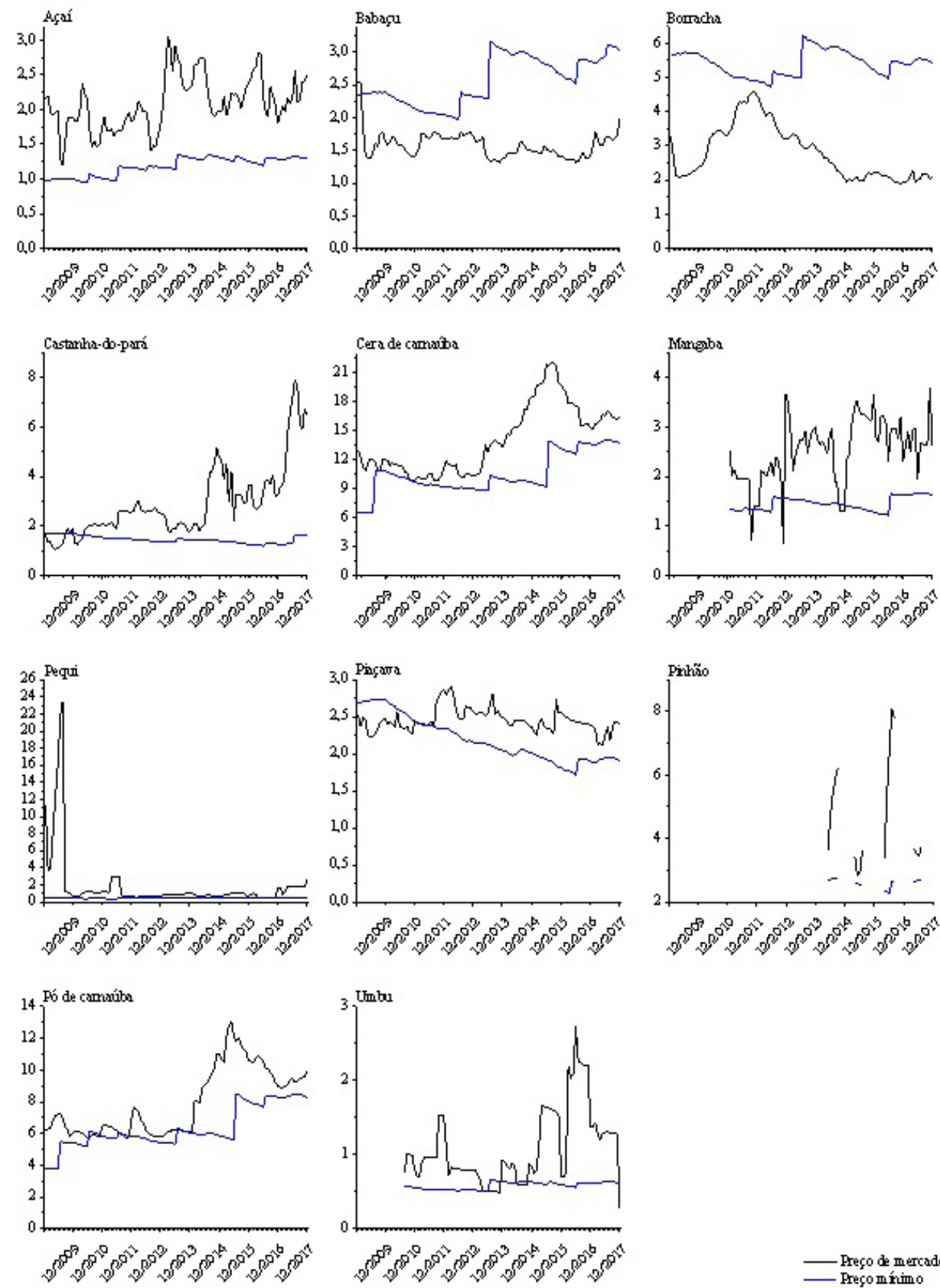

Fonte: elaborado pelas autoras, a partir de dados básicos da CONAB (2018). 
Tendo em vista que os preços mínimos exprimem os custos de produção, atina-se que os cenários do babaçu e da borracha são alarmantes, pois patenteiam que a remuneração dos extrativistas não paga seus custos variáveis de produção, o que desestimula a continuidade da mão de obra nessas atividades e explica a tendência declinante da produção.

Nesse sentido, a subvenção paga aos extrativistas, por meio da PGPMBio, mostra-se um instrumento relevante por cobrir essa diferença de preços. Em concordância com Souza (2017), o baixo preço de mercado do babaçu justifica-se pela concorrência com outros produtos mais conhecidos ou mais baratos. Já a borracha, segundo Pennacchio (2018), tem seu preço determinado no mercado externo e registra decréscimos especialmente desde 2011, comprometendo a produção devido ao fechamento de usinas de beneficiamento em todos os estados da Região Norte.

Ao analisarem a cadeia produtiva de pinhão, em 2010 - ano em que a CONAB calculou o custo de produção desse produto -, Ribeiro, Santos e Bittencourt (2015) aduziram que ele ainda não fazia parte dos beneficiários da política. Outrossim, os autores constataram que a inclusão do pinhão na PGPM melhoraria a situação econômica desses produtores, uma vez que os preços de venda se situavam em patamares inferiores aos custos de produção.

Diante do exposto, entre 2009 e 2017, a participação dos produtos da sociobiodiversidade na economia nacional foi relativamente pouco expressiva, principalmente pelo fato de sua comercialização ser realizada sem agregação de valor e, em alguns casos, sem cobrir sequer seus custos de produção. Daí a importância da PGPM-Bio, complementando a renda desses extrativistas e garantindo o ínfimo para sua subsistência.

Não obstante, essa política ainda pode ter mais espaço para ação, desde que seja amplamente divulgada entre os produtores.

\section{CONCLUSÕES}

A PGPM-Bio desempenha um papel importante na conservação ambiental, haja vista a sua proposta de integração: econômica, ao fornecer renda e garantir o emprego dos extrativistas; social, ao manter o conhecimento 
e a prática de saberes dos povos e comunidades tradicionais; e ambiental, ao asseverar o interesse do produtor em perpetuar as espécies nativas, já que somente por meio delas é possível obter benefícios, garantias de renda e o fortalecimento de mercado.

Quanto à representatividade econômica do segmento extrativo, notou-se que ele agrega pouco valor à produção total do País, visto que se trata de matérias-primas. Aliás, em comparação com os demais setores, o agropecuário figurou-se com a maior oscilação do valor adicionado bruto, entre os anos de 2002 e 2015.

As Regiões Norte e Nordeste são as mais proeminentes nesse ramo, corroborando o fato de serem menos industrializadas e urbanizadas. Entre os produtos estudados, o açaí e o pó de carnaúba destacam-se como os que acrescentam mais valor à produção total extrativa.

Em relação à atuação da PGPM-Bio, os estados do Maranhão, da Bahia e do Amazonas sobressaíram-se, apresentando os maiores valores subvencionados, destinados, respectivamente, ao babaçu, à piaçava e à borracha.

Apesar da sua importância econômica, fortalecendo o segmento extrativo, admite-se que os benefícios da PGPM-Bio podem ser ampliados, tendo em vista que o valor orçado para cobrir as demandas de subvenção econômica, em cada ano, não chegou a ser usado em sua totalidade, restando mais da metade do volume de recursos destinados a esse fim.

Isso posto, identificaram-se algumas limitações à execução dessa política, a exemplo de: preços mínimos abaixo dos de mercado; desconhecimento da sua existência por parte dos extrativistas; exigência de documentação, como a nota fiscal e a DAP, as quais, apesar de burocratizarem o andamento da operação, representam os requisitos mínimos para comprovação do preço de venda, bem como para ter acesso ao auxílio governamental.

Desse modo, para que o funcionamento da PGPM-Bio seja aprimorado, aliando aspectos econômicos, sociais e ambientais, faz-se necessário um remodelamento em sua dinâmica. Sugere-se, nesse caso, a inclusão do custo socioambiental na composição/elaboração dos preços mínimos, garantindo maior valorização desses produtos, bem como ampliar a divulgação e facilitar o acesso a essa política. 


\section{REFERÊNCIAS}

ALICEWEB. Banco de dados do Ministério da Indústria e Comércio Exterior. Exportação de ceras vegetais. 2018. Disponível em: http://aliceweb2.mdic. gov.br. Acesso em: 17 out. 2018.

ARBACHE, J. Produtividade no setor de serviços. In: Negri, F.; Cavalcante, L. R. (Org.). Produtividade no Brasil: desempenho e determinantes. Brasília: IPEA, 2015. p. 277-300.

BRASIL. Ministério do Desenvolvimento Agrário; Ministério do Meio Ambiente; Ministério de Desenvolvimento Social e Combate à Fome. Plano Nacional de Promoção de Cadeias de Produtos da Sociobiodiversidade. Brasília-DF: MDA; MMA; MDS, 2010. Disponível em: http://comunidades. mda.gov.br/portal/saf/arquivos/view/sociobiodiversidade/PLANO_ NACIONAL_DA_SOCIOBIODIVERSIDADE-julho-2009.pdf. Acesso em: 11 abr. 2018.

BRASIL. Ministério da Agricultura, Pecuária e Abastecimento. Preços mínimos para os produtos da sociobiodiversidade. Brasília-DF, 2009. Disponível em: http://www.agricultura.gov.br. Acesso em: 11 abr. 2018.

BRASIL. Decreto n. 6.040, de 7 de fevereiro de 2007. Institui a Política Nacional de desenvolvimento Sustentável dos Povos e Comunidades Tradicionais. Diário Oficial [da] República Federativa do Brasil, Poder Executivo, Brasília-DF, n. 28, 8 fev. 2007, Seção 1, p. 316-317.

BRASIL. Decreto n. 4.339, de 22 de agosto de 2002. Institui princípios e diretrizes para a implementação da Política Nacional da Biodiversidade. Diário Oficial [da] República Federativa do Brasil, Poder Executivo, BrasíliaDF, n. 163, 23 ago. 2002, Seção 1, p. 2-9.

CARVALHO, M. A.; SILVA, C. R. L. Preços mínimos e estabilização de preços agrícolas. Revista de Economia Política, São Paulo, v. 13, n. 49, p. 52-63, 1993.

CERQUEIRA, E. B.; GOMES, J. M. Sociobiodiversidade, mercado e política de preços mínimos para pó e cera de carnaúba. Espacios, Caracas, v. 36, n. 10, p. 10, 2015.

COELHO, C. N. 70 anos de política agrícola no Brasil (1931-2001). Revista de Política Agrícola, Brasília, v. X, n. 3, p. 1-58. Edição Especial, 2001. 
COMPANHIA NACIONAL DE ABASTECIMENTO [CONAB]. [mensagem pessoal]. Dados sobre a PGPM-Bio. Mensagem recebida por: emilianacerq@gmail. com, em 2 jul. 2018.

DELGADO, G. C.; CONCEIÇÃO, J. Políticas de preços agrícolas e estoques de alimentos: origens, situação atual e perspectivas. Revista Paranaense de Desenvolvimento, Curitiba, v. 108, p. 25-32, 2005.

FAVRO, J.; CALDARELLI, C. E.; CARAVIERI, A. M. M. A Política de Garantia de Preços Mínimos antes e pós-Plano Real. Economia \& Região, Londrina, v. 2, n. 2, p. 65-79, 2014.

INSTITUTO BRASILEIRO DE GEOGRAFIA E ESTATÍSTICA. Produção da Extração Vegetal e da Silvicultura. Rio de Janeiro: IBGE, 2016. Disponível em: https:// sidra.ibge.gov.br/tabela/289. Acesso em: 9 abr. 2018.

INSTITUTO BRASILEIRO DE GEOGRAFIA E ESTATÍSTICA. Produto Interno Bruto dos Municípios. Rio de Janeiro: IBGE, 2015. Disponível em: https://www. ibge.gov.br/estatisticas-novoportal/economicas/contas-nacionais/9088produto-interno-bruto-dos-municipios. html?=\&t=downloads. Acesso em: 9 abr. 2018.

LIMA, C. V. S.; CARDOSO JR., H. M.; LUNAS, D. A. L. A política de garantia de preços mínimos para produtos da sociobiodiversidade (PGPM-Bio): potencialidades da intervenção estatal para a conservação ambiental em Goiás. Guaju, Matinhos, v. 3, n. 1, p. 37-65, 2017.

NOGUEIRA, A. K. M.; SANTANA, A. C.; GARCIA, W. S. A dinâmica do mercado de açaí fruto no Estado do Pará: de 1994 a 2009. Revista Ceres, Viçosa, v. 60 , n. 3, p. 324-31, 2013.

PENNACCHIO, H. L. Borracha natural extrativa. Companhia Nacional de Abastecimento [CONAB]. Boletim da Sociobiodiversidade, Brasília, v. 2, n. 1, p. 30-1, 2018.

PINDICK, R. S.; RUBINFELD, D. L. Microeconomia. 5. ed. Tradução e revisão técnica de Eleutério Prado. São Paulo, SP: Prentice Hall, 2002.

RIBEIRO, R. M.; SANTOS, A. J.; BITTENCOURT, A. A política de garantia de preços mínimos para o pinhão. Pesquisa Florestal Brasileira, Brasília, v. 35, n. 84, p. 459-68, 2015. 
SOUZA, E. C. M. Babaçu. Companhia Nacional de Abastecimento [CONAB]. Boletim da sociobiodiversidade, Brasília, n. 1, v. 2, p. 20-3, 2017.

SOUZA, C. Políticas Públicas: uma revisão da literatura. Sociologias, Porto Alegre, v. 8, n. 16, p. 20-45, 2006.

VIANA, J. P. Operacionalização da Política de Garantia de Preços Mínimos para produtos da sociobiodiversidade 2009-2013: há espaço para crescer. Brasília: Ipea, 2015. [Texto para discussão/Instituto de Pesquisa Econômica Aplicada]

VIEIRA, L. F. Agricultura e agroindústria familiar. Revista de Política Agrícola, Brasília, v. VII, n. 1, p. 14-31, 1998. 